\title{
Epidemiological Correlation of Pulmonary Aspergillus Infections with Ambient Pollutions and Influenza A (H1N1) in Southern Taiwan
}

\author{
Jien-Wei Liu ${ }^{1,2, \dagger}$, Yee-Huang $\mathrm{Ku}^{3,+}$, Chien-Ming Chao ${ }^{3}$, Hsuan-Fu Ou ${ }^{4}$, Chung-Han Ho ${ }^{5,6} \mathbb{D}, \mathrm{Khee}^{3}$-Siang Chan ${ }^{7}$ \\ and Wen-Liang Yu 7,8,*(D)
}

Citation: Liu, J.-W.; Ku, Y.-H.; Chao, C.-M.; Ou, H.-F.; Ho, C.-H.; Chan, K.-S.; Yu, W.-L. Epidemiological Correlation of Pulmonary Aspergillus Infections with Ambient Pollutions and Influenza A (H1N1) in Southern Taiwan. J. Fungi 2021, 7, 227.

https://doi.org/10.3390/jof7030227

Academic Editor: David Perlin

Received: 28 February 2021

Accepted: 17 March 2021

Published: 19 March 2021

Publisher's Note: MDPI stays neutral with regard to jurisdictional claims in published maps and institutional affiliations.

Copyright: (c) 2021 by the authors. Licensee MDPI, Basel, Switzerland. This article is an open access article distributed under the terms and conditions of the Creative Commons Attribution (CC BY) license (https:/ / creativecommons.org/licenses/by/ $4.0 /)$.
1 Division of Infectious Diseases, Department of Internal Medicine, Kaohsiung Chang Gung Memorial Hospital, Kaohsiung 83301, Taiwan; 88b0@cgmh.org.tw

2 Chang Gung University College of Medicine, Taoyuan 333323, Taiwan

3 Department of Intensive Care Medicine, Chi Mei Medical Center, Liouying, Tainan 73657, Taiwan; althrisas@gmail.com (Y.-H.K.); ccm870958@yahoo.com.tw (C.-M.C.)

4 Department of Intensive Care Medicine, Chi Mei Medical Center, Chiali, Tainan 72263, Taiwan; Iamkiu@gmail.com

5 Department of Medical Research, Chi Mei Medical Center, Tainan 71004, Taiwan; ho.c.hank@gmail.com

6 Department of Hospital and Health Care Administration, Chia Nan University of Pharmacy \& Science, Tainan 71710, Taiwan

7 Department of Intensive Care Medicine, Chi Mei Medical Center, Tainan 71004, Taiwan; kheesiangchan@gmail.com

8 Department of Medicine, School of Medicine, College of Medicine, Taipei Medical University, Taipei 11031, Taiwan

* Correspondence: yuleon_md@yahoo.com.tw; Tel.: +886-6-2812811; Fax: +886-6-2833351

+ These authors share the same contribution to the paper.

Abstract: An increase in fungal spores in ambient air is reported during a spike in particulate matter $\left(\mathrm{PM}_{2.5}\right.$ and $\left.\mathrm{PM}_{10}\right)$ aerosols generated during dust or smog events. However, little is known about the impact of ambient bioaerosols on fungal infections in humans. To identify the correlation between the incidence of pulmonary aspergillosis and PM-associated bioaerosols $\left(\mathrm{PM}_{2.5}\right.$ and $\left.\mathrm{PM}_{10}\right)$, we retrospectively analyzed data between 2015 and 2018 (first stage) and prospectively analyzed data in 2019 (second stage). Patient data were collected from patients in three medical institutions in Tainan, a city with a population of 1.88 million, located in southern Taiwan. PM data were obtained from the Taiwan Air Quality Monitoring Network. Overall, 544 non-repeated aspergillosis patients (first stage, $n=340$; second stage, $n=204$ ) were identified and enrolled for analysis. The trend of aspergillosis significantly increased from 2015 to 2019. Influenza A (H1N1) and ambient PMs (PM 2.5 and $\mathrm{PM}_{10}$ ) levels had significant effects on aspergillosis from 2015 to 2018 . However, ambient PMs and influenza A (H1N1) in Tainan were correlated with the occurrence of aspergillosis in 2018 and 2019, respectively. Overall (2015-2019), aspergillosis was significantly correlated with influenza $(p=0.002)$, influenza A (H1N1) $(p<0.001)$, and $\mathrm{PM}_{2.5}(p=0.040)$ in Tainan City. Using a stepwise regression model, influenza A (H1N1) $(p<0.0001)$ and Tainan $\mathrm{PM}_{10}(p=0.016)$ could significantly predict the occurrence of aspergillosis in Tainan. PM-related bioaerosols and influenza A (H1N1) contribute to the incidence of pulmonary aspergillosis.

Keywords: aspergillosis; fungus; influenza A (H1N1); $\mathrm{PM}_{2.5} ; \mathrm{PM}_{10}$; pollution

\section{Introduction}

Particulate matter (PM) is complex mixture of both organic and inorganic particles, including microorganisms. Of note, fungal spores (e.g., Aspergillus spores) have been widely reported to be part of ambient bioaerosols in PM. Conventionally categorized PMs include $\mathrm{PM}_{2.5}$ and $\mathrm{PM}_{10}$ (mean aerodynamic diameters $\leq 2.5 \mu \mathrm{m}$ and $\leq 10 \mu \mathrm{m}$, respectively). The measurement unit of PM is generally micrograms per cubic meter $\left(\mu \mathrm{g} / \mathrm{m}^{3}\right)$. Aspergillus 
fumigatus is an airborne saprophytic fungus. The conidia released into the earth's atmosphere have a diameter small enough $(2$ to $3 \mu \mathrm{m})$ to settle onto microenvironments in the small particles of $\mathrm{PM}_{2.5}$ or $\mathrm{PM}_{10}$. Quantitative evaluation of fungal exposure is often conducted by analysis of the composition of fungal spores in air samples and calculation of the concentrations afterward [1-4].

Ambient Aspergillus spore counts were found to significantly increase from 247 spores $/ \mathrm{m}^{3}$ in air pollutant $\mathrm{PM}_{10}$ of $84 \mu \mathrm{g} / \mathrm{m}^{3}$ to 975 spores $/ \mathrm{m}^{3}$ in $\mathrm{PM}_{10}$ of $103 \mu \mathrm{g} / \mathrm{m}^{3}$ during dust events between December 2000 and April 2001 in Tainan, a city with a population of 1.88 million located in southern Taiwan [1]. An increase in the burdens of Aspergillus fulmigatus in air pollutants $\mathrm{PM}_{2.5}$ and $\mathrm{PM}_{10}$ was reported during a smog event in Beijing [2]. Despite the well-documented parallel increase in fungal spores in ambient air and PMs $\left(\mathrm{PM}_{2.5}\right.$ and $\left.\mathrm{PM}_{10}\right)$ generated in dust or smog events [1-4], little is known about the impact of ambient bioaerosols with airborne fungal spores on pulmonary aspergillosis in humans.

Unlike classical invasive pulmonary aspergillosis (IPA) with pulmonary cavitary lesions in the severely immunocompromised patients, higher chances of IPA in patients with clinically severe influenza were reported to have various types of pulmonary lesions [5-9]. IPA could also occur in patients with modified immune impaired disorders or in critically ill patients, who are potentially vulnerable to IPA [10]. Because of the presence of $17 \%$ of IPA in patients suffering from clinically severe influenza in Tainan [8] and a prior high-level ambient $\mathrm{PM}_{2.5}$ for 2 months ( $>54 \mu \mathrm{g} / \mathrm{m}^{3}$ over $100 \mathrm{~h}$ per month), we previously proposed that there was a correlation between ambient air pollution and increased suspended $\mathrm{PM}_{2.5}$ and the soaring incidences of IPA in severe influenza patients [9]. Therefore, we designed this current study to analyze the trend of monthly total IPA cases based on presumably stable numbers of monthly administered patients in our intensive care units (ICUs) [9]. We also used \% of IPA in the severe (hospitalized in ICU) influenza patients, which could be comparative to published data [5-8]. The goals of this study were to document the epidemiological linkage between air pollution and IPA patients of all hosts, but not limited to the influenza patients only. We hypothesized that IPA patients would increase in the seasons of higher PM bioaerosols and during an influenza epidemic. Elucidation of this correlation may help public health authorities to map out a plan to mitigate IPA, especially in dust events and influenza seasons.

\section{Materials and Methods}

We included and analyzed patients with IPA and patients with confirmed influenza admitted between 2015 and 2019 at any of the three institutions of Chi Mei medical systems scattered in different districts in Tainan City, including Chi Mei Medical Center (1278bed tertiary referral teaching medical center), Chi Mei Medical Center, Liouying (876-bed regional teaching hospital), and Chi Mei Medical Center, Chiali (333-bed local teaching hospital). These facilities were located at least $40-50 \mathrm{Km}$ apart from each other. A two-phase analytical study was conducted, with (1) phase 1 , where patients admitted between January 2015 and December 2018 were retrospectively included for analysis, and (2) phase 2, where patients admitted between January and December 2019 were prospectively included in an observational study. Laboratory data were obtained from the electronic resources of the Chi Mei medical systems.

IPA was defined as a concurrent pneumonia and positive test for Aspergillus galactomannan (GM) antigen from serum, bronchoalveolar lavage fluid (BAL) and/or endobronchial secretion. Pneumonia was defined as mentioned elsewhere [11]. GM antigen was detected using Platelia Aspergillus Ag EIA (Bio-Rad Laboratories, Marnes-La-Coquette, France), where a cut-off value $\geq 0.5$ indices indicated a positive result [10]. The IPA patients were not limited to any host factor, modified from the newly updated consensus definitions of invasive fungal disease from the European Organization for Research and Treatment of Cancer (EORTC) and the Mycoses Study Group Education and Research Consortium [12], which proposed probable IPA requiring the presence of at least one host factor (immunocompromised patients only), a clinical feature (computed tomogra- 
phy image), and mycologic evidence. The updated EORTC consensus defined positive GM antigen for any 1 of the following: $\geq 1.0$ for single serum or plasma, $\geq 1.0$ for BAL fluid, and single serum or plasma $\geq 0.7$ plus BAL fluid $\geq 0.8$ [12]; whereas we enrolled all IPAs in immunocompromised and non-immunocompromised hosts including severe influenza patients, who had pneumonia and a GM antigen $\geq 0.5$ for serum, BAL, and/or endobronchial secretion.

Diagnosis of influenza was made based on a throat swab positive for influenza test using one of the following polymerase chain reaction (PCR) analyses: for influenza A, influenza $\mathrm{A}(\mathrm{H} 1 \mathrm{~N} 1)$, influenza $\mathrm{A}(\mathrm{H} 3 \mathrm{~N} 2)$, or influenza B. Severe influenza referred to any clinically severe influenza infection making intensive monitoring and advanced supportive care indicated for the affected patient admitted to an ICU. Severe influenza is a notifiable disease in Taiwan and is required by law to be reported to Taiwan CDC, where the influenza A should be subtyped to determine whether it is H1N1 or H3N2. Non-typed influenza A was applicable to those not requiring ICU admission and there is no need for a CDC report. Information regarding monthly mean values of PMs that indicated levels of air pollution for differing cities/districts in Taiwan was retrieved from the Taiwan Air Quality Monitoring Network, which monitors the long-term trend of air quality from 60 general monitoring stations throughout Taiwan run by the Environmental Protection Administration, Executive Yuan. General monitoring stations were installed at populous sites or sites that are prone to higher pollution or can represent the distribution of air quality in a larger area, so that the data collected can reflect the air quality status of people's daily lives (https:/ / airtw.epa.gov.tw/ENG/ default.aspx, accessed on 16 January 2021).

The trend of variables and the slope difference in comparison were calculated using the Theil-Sen trend test (http:/ / www.singlecaseresearch.org/calculators/theil-sen, accessed on 16 January 2021). Spearman's test and logistic regression were used to measure the correlation and prediction between two variables, respectively. SAS 9.4 for Windows (SAS Institute, Inc., Cary, NC, USA) was used for statistical analyses.

\section{Results}

\subsection{Trend Analysis}

Overall, 544 non-repeated IPA patients (first stage, $n=340$; second stage, $n=204$ ) were identified from 2015 to 2019. These patients were all putative/probable IPA according to the modified AspICU algorithm proposed by Schroeder et al. [10]. Positive Aspergillus GM tests were mainly based on positivity for blood samples $(n=369,68 \%)$, endobronchial secretions $(n=88,16 \%)$, BAL $(n=81,15 \%)$, and endobronchial fungal cultures $(n=6,1 \%)$. Positive non-blood samples were not calculated if blood samples were positive. Positive Aspergillus cultures were not calculated if other samples were positive. Among 204 IPA patients in the observational prospective study in 2019, the proportion of positive sample was: $54.2 \%$ (103/190) for blood, $85.5 \%$ (106/124) for endobronchial secretion, and $78.3 \%$ $(18 / 23)$ for BAL fluid. The proportion of GM antigen $\geq 1.0$ in positive samples was $51.5 \%$ (53/103) for blood, 65.1\% (69/106) for endobronchial secretion, and 55.6\% (10/18) for BAL fluid.

Table 1 presents trends of all different time periods (2015-2016, 2015-2017, 2015-2018, and 2015-2019), and compares 2015-2017 vs. 2018-2019. There were significant increases in 2015-2018, 2018-2019, and 2015-2019. These data highlighted that the increase from 2018 to 2019 is due to the prospective study, but IPA had also increased from 2015 to 2018. 
Table 1. Monthly cases of pulmonary aspergillosis and secular trend analysis from 2015 to 2019.

\begin{tabular}{|c|c|c|c|c|c|c|}
\hline Year & $2015^{a}$ & $2016^{a}$ & $2017^{a}$ & $2018^{a}$ & $2019^{b}$ & $p$ for mean \\
\hline Mean & 4.75 & 8.58 & 5.75 & 9.25 & 17.00 & $<0.0001$ \\
\hline $\mathrm{SD}$ & 1.82 & 9.20 & 3.19 & 3.74 & 5.05 & \\
\hline Slope & 0 & -0.394 & 0.134 & -0.444 & 0.171 & \\
\hline CI $90 \%$ & $(0,0)$ & $(-1.024,0.236)$ & $(-0.325,0.593)$ & $(-1.333,0.444)$ & $(-0.240,0.583)$ & \\
\hline$P$ for slope & 0.681 & 0.303 & 0.631 & 0.411 & 0.493 & \\
\hline Year & & 016 & 2015-2017 & 2015-2018 & 2015-2019 & \\
\hline Slope & & & 0 & 0.077 & 0.185 & \\
\hline CI $90 \%$ & & & $(0,0)$ & $(0.021,0.133)$ & $(0.122,0.248)$ & \\
\hline$P$ for slope & & & 0.806 & 0.023 & $<0.00001$ & \\
\hline Year & & 2015-2017 & & 2018 & 2019 & \\
\hline Slope & & 0 & & & & \\
\hline CI $90 \%$ & & $(0,0)$ & & $(0.20 s$ & $0.791)$ & \\
\hline$P$ for slope & & 0.806 & & & & \\
\hline Year & \multicolumn{5}{|c|}{ 2015-2017 vs. 2018-2019 } & \\
\hline \multirow{3}{*}{$\begin{array}{c}\text { Slope difference } \\
\text { CI } 90 \% \\
p \text { for slope } \\
\text { difference }\end{array}$} & \multirow{2}{*}{\multicolumn{5}{|c|}{$\begin{array}{c}-0.500 \\
(0,0)\end{array}$}} & \\
\hline & & & & & & \\
\hline & \multicolumn{5}{|c|}{0.005} & \\
\hline
\end{tabular}

a, retrospective data; $b$, prospective data; $\mathrm{SD}$, standard deviation; $\mathrm{CI}$, confidence interval.

Except for a spike in IPA cases found in early 2016, IPA monthly cases in 2019 (mean $=17.0, \mathrm{SD}=5.05)$ were the highest during 2015-2019 $($ mean $=9.07, \mathrm{SD}=6.73$, $p<0.0001$, Table 1). The trend of IPA significantly increased from 2015 to 2019 (slope, 0.185; $p<0.00001$ ), with the most significant increase from 2018 to 2019, thus leading to a significant change between the trends of 2015-2017 and 2018-2019 (slope difference, -0.5 and $p=0.005$ ). The trend in IPA within each year did not change significantly (Table 1 ), but a dynamic variance existed and was often the highest in the winter-spring seasons and lowest in the summer seasons (Figure 1).

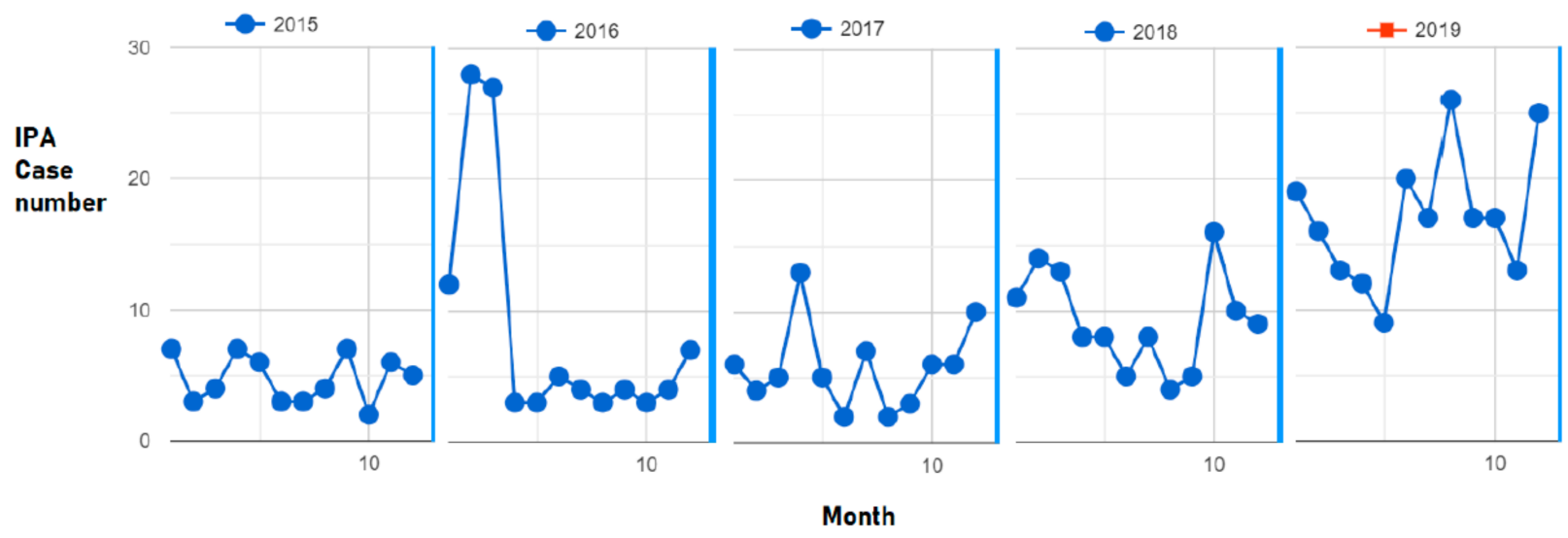

Figure 1. Invasive pulmonary aspergillosis (IPA)cases per month in 2019 are significantly higher than those in 2015-2018 and the trends of IPA cases show a significant increase from 2018 to 2019 (slope, 0.500, $p=0.005$ ) and 2015 to 2019 (slope, $0.185 ; p<0.00001$ ).

The secular trend (2015-2019) of monthly average of $\mathrm{PM}_{2.5}$ in Tainan City insignificantly decreased $(p=0.3387)$. However, the trend of monthly cases of influenza A (H1N1) significantly increased (slope, 0.0357; $p=0.001$ ) from 2015 to 2019 (see Supplementary Figure S1). 


\subsection{Correlation Analysis \\ 3.2.1. First Stage (2015-2018)}

Although influenza A (H1N1) influenza circulated predominantly in 2016, a yearlybasis increase in IPA cases was not found in 2016 ( $p=0.111)$, but influenza A (H1N1) had a significant correlation with the 4-year secular trend of IPA from 2015 to $2018(p=0.042)$. Overall influenza, non-typed influenza A, influenza A (H3N2), and influenza B had no significant correlation with the secular trend of IPA in 2015-2018 (Table 2). The air pollution in Tainan has no statistically significant correlation with \% of IPA in severe influenza patients $(13.0 \%, 41 / 315)$ during the 48 -month period (Table 3$)$.

Table 2. Spearman's correlation between IPA case number and each variable, including all influenza, subtypes of influenza, and ambient pollution in Tainan.

\begin{tabular}{|c|c|c|c|c|c|c|c|}
\hline $\begin{array}{l}\text { IPA in } 3 \text { Tainan } \\
\text { Institutes }(n)\end{array}$ & $\begin{array}{l}\text { Influenza(all) } \\
\text { ( } n, p \text { Values) }\end{array}$ & $\begin{array}{c}\text { Flu A } \\
\text { (H3N2) } \\
(n, p \text { Values) }\end{array}$ & $\begin{array}{c}\text { Non-typed } \\
\text { FluA } \\
\text { ( } n, p \text { Values) }\end{array}$ & $\begin{array}{c}\text { Influenza B } \\
\text { ( } n, p \text { Values) }\end{array}$ & $\begin{array}{c}\text { Flu A } \\
\text { (H1N1) } \\
(n, p \text { Values) }\end{array}$ & $\begin{array}{c}\mathrm{PM}_{2.5} \text { in } \\
\text { Tainan }\end{array}$ & $\begin{array}{c}\mathrm{PM}_{10} \text { in } \\
\text { Tainan }\end{array}$ \\
\hline \multicolumn{8}{|c|}{ Retrospective (Stage 1) } \\
\hline $2015(57)$ & $92,0.710$ & $32,0.479$ & $32,0.906$ & $15,0.526$ & $13,0.882$ & 0.122 & 0.455 \\
\hline $2016(103)$ & $235,0.039$ & $12,0.654$ & $94,0.077$ & $32,0.089$ & $97,0.111$ & 0.094 & 0.078 \\
\hline $2017(69)$ & $133,0.203$ & $72,0.627$ & $56,0.041 *$ & $4,0.466$ & $1,0.785$ & 0.284 & 0.121 \\
\hline $2018(111)$ & $89,0.792$ & $29,0.257$ & $20,0.271$ & $23,0.220$ & $17,0.698$ & 0.002 & 0.005 \\
\hline Subtotal (340) & $549,0.340$ & $145,0.335$ & $202,0.567$ & $74,0.301$ & $128,0.042$ & 0.001 & 0.001 \\
\hline \multicolumn{8}{|c|}{ Prospective (Stage 2) } \\
\hline $2019(204)$ & $165,0.198$ & $27,0.956$ & $62,0.724$ & $2,0.892$ & $78,0.015$ & 0.334 & 0.552 \\
\hline Overall (544) & $714,0.002$ & $171,0.506$ & $261,0.124$ & $76,0.697$ & $206,<0.001$ & 0.040 & 0.061 \\
\hline
\end{tabular}

Table 3. Spearman's correlation between \% of IPA in severe influenza and each variable, including \% of IPA in subtypes of severe influenza and ambient pollution in Tainan.

\begin{tabular}{|c|c|c|c|c|c|c|}
\hline $\begin{array}{l}\text { IPA in Severe Influenza } \\
\qquad(\%, n / \mathrm{N})\end{array}$ & $\begin{array}{c}\text { IPA in Severe } \\
\text { H1N1 } \\
(\%, n / \mathrm{N})\end{array}$ & $\begin{array}{c}\text { IPA in Severe } \\
\text { H3N2 } \\
(\%, n / \mathrm{N})\end{array}$ & $\begin{array}{c}\text { IPA in Severe } \\
\text { other Flu A } \\
(\%, n / \mathrm{N})\end{array}$ & $\begin{array}{c}\text { IPA in Severe } \\
\text { Flu B } \\
(\%, n / \mathrm{N})\end{array}$ & $\begin{array}{l}\text { Tainan } \\
\text { PM }_{2.5}\end{array}$ & $\begin{array}{c}\text { Tainan } \\
\text { PM }_{10}\end{array}$ \\
\hline \multicolumn{7}{|l|}{ Retrospective (Stage 1) } \\
\hline $2015(11.3,7 / 62)$ & $8.3,1 / 12$ & $10.7,3 / 28$ & $13.3,2 / 15$ & $14.3,1 / 7$ & 0.654 & 0.787 \\
\hline $2016(16,2,22 / 136)$ & $16.7,13 / 78$ & $0,0 / 12$ & $34.6,9 / 26$ & $0,0 / 20$ & 0.058 & 0.064 \\
\hline $2017(3.2,2 / 62)$ & $0,0 / 0$ & $1.8,1 / 57$ & $0,0 / 2$ & $33.3,1 / 3$ & 0.894 & 0.809 \\
\hline $2018(18.2,10 / 55)$ & $7.7,1 / 13$ & $11.1,3 / 27$ & $25,1 / 4$ & $45.5,5 / 11$ & 0.403 & 0.738 \\
\hline Subtotal $(13.0,41 / 315)$ & $14.6,15 / 103$ & $5.6,7 / 124$ & $25.5,12 / 47$ & $17.1,7 / 41$ & & \\
\hline$P$ for $2015-2018$ & 0.007 & $<0.001$ & 0.004 & $<0.001$ & 0.189 & 0.198 \\
\hline \multicolumn{7}{|l|}{ Prospective (Stage 2) } \\
\hline $2019(21.7,20 / 92)$ & $27.9,19 / 68$ & $0 / 20$ & $33.3,1 / 3$ & $0 / 1$ & & \\
\hline $\begin{array}{c}\text { P for } 2019 \\
\text { Overall }\end{array}$ & $<0.001$ & NA & 0.786 & NA & 0.221 & 0.427 \\
\hline 2015-2019 (15.0, 61/407) & $19.9,34 / 171$ & $4.9,7 / 144$ & $26.0,13 / 50$ & $16.7,7 / 42$ & & \\
\hline$P$ for $2015-2019$ & $<0.001$ & 0.003 & 0.010 & $<0.001$ & 0.201 & 0.203 \\
\hline
\end{tabular}

Note. Other Flu A indicates non-H1N1, non-H3N2 severe influenza A, responsible for 18.4\% (48/261) of non-typed Flu A (mostly influenza A without further identification).

Ambient air pollution $\left(\mathrm{PM}_{2.5}\right.$ and $\left.\mathrm{PM}_{10}\right)$ levels in Tainan City was significantly correlated with IPA in 2018 solely, and with a longer time interval from 2015 to 2018 (Table 2). There were similar annual average concentrations of $\mathrm{PM}_{2.5}$ among the three zones of the closest reporting station to each hospital in Tainan City (Figure 2). The gradient of local ambient $\mathrm{PM}_{2.5}$ concentration was generously highest in southern Taiwan, moderate in central Taiwan, lower in northern Taiwan and lowest in eastern Taiwan (like the data in 2018, see Supplementary Figure S2A). Tainan IPA, typically in 2018, was correlated significantly with ambient $\mathrm{PM}_{2.5}$ of local areas (such as Tainan West-Central District and 
Zuoying District) in southern Taiwan, extending to the Xitun District of Taichung City in central Taiwan, but was not correlated to ambient $\mathrm{PM}_{2.5}$ in more distant areas, such as northern and eastern Taiwan, with an interface in central Taiwan (see Supplementary Figure S2B). Tainan IPA was also significantly correlated with $\mathrm{PM}_{10}$ at Tainan (West-Central area), Xinying, and Zuoying areas in 2018 (see Supplementary Figure S3).

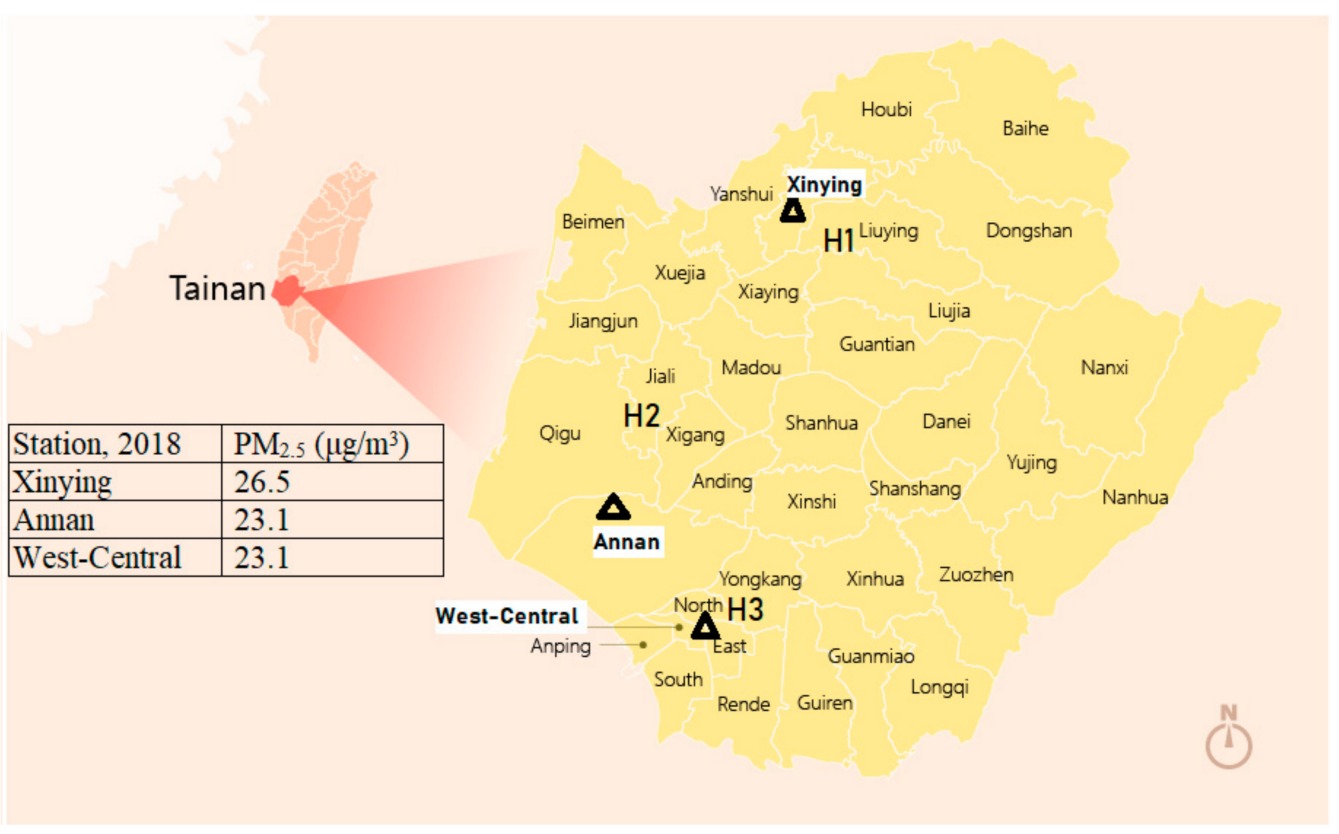

Figure 2. A map of Tainan City with the closest reporting station to each hospital: Xinying station closest to Chi Mei Medical Center, Liouying (H1); Annan station closest to Chi Mei Medical Center, Chali (H2); and West-Central station closest to Chi Mei Medical Center, Tainan (H3), showing no significant difference of $\mathrm{PM}_{2.5}$ among the three zones in Tainan.

\subsubsection{Second Stage (2019)}

Influenza A (H1N1), but not air pollution in Tainan, was significantly correlated with the occurrence of IPA. Overall influenza, non-typed influenza A, influenza A (H3N2), and influenza B had no significant correlation with the occurrence of IPA in 2019 (Table 2). Air pollution in Tainan had no statistically significant association with \% of IPA in severe influenza patients $(21.7 \%, 20 / 92)$ during the 12 -month period (Table 3$)$. The $\%$ of IPA in severe influenza during the prospective stage was significantly higher than that of the retrospective stage $(21.7 \%$ vs. $13.0 \%, p=0.039$, chi-square statistic test).

\subsubsection{Overall (2015-2019)}

IPA was significantly linked to all influenza $(p=0.002)$, influenza A (H1N1) $(p<0.001)$, and $\mathrm{PM}_{2.5}(p=0.040)$ in Tainan City (Table 2$)$. The air pollution in Tainan has no statistically significant association with \% of IPA in severe influenza patients $(15.0 \%, 61 / 407)$ during the 60-month period (Table 3). The ambient $\mathrm{PM}_{2.5}$ in areas other than Tainan City was not correlated with Tainan IPA (see Supplementary Figure S4). The $\mathrm{PM}_{2.5}$ gradient in Taiwan was usually higher in the southern area than in the central area and lower in the northern area (lowest in the eastern area, not shown).

The peak of $\mathrm{PM}_{2.5}$ usually occurred in the spring and the trough occurred in summer, generally compatible with the trend of case number of IPA (Figure 3). The monthly case number of IPA usually peaked in the spring, compatible with the peak seasons of $\mathrm{PM}_{2.5}$. An unusual IPA surge occurred in autumn 2019 during the lowest levels of $\mathrm{PM}_{2.5}$, while an influenza (H1N1) epidemic unusually occurred in the same season (Figure 3). The IPA trend had no statistically significant correlation with influenza A (H3N2) and influenza B. 
For example, a summer epidemic influenza (H3N2) occurred during the trough levels of $\mathrm{PM}_{2.5}$ in 2017, but it was not accompanied by an IPA surge (Figure 3).

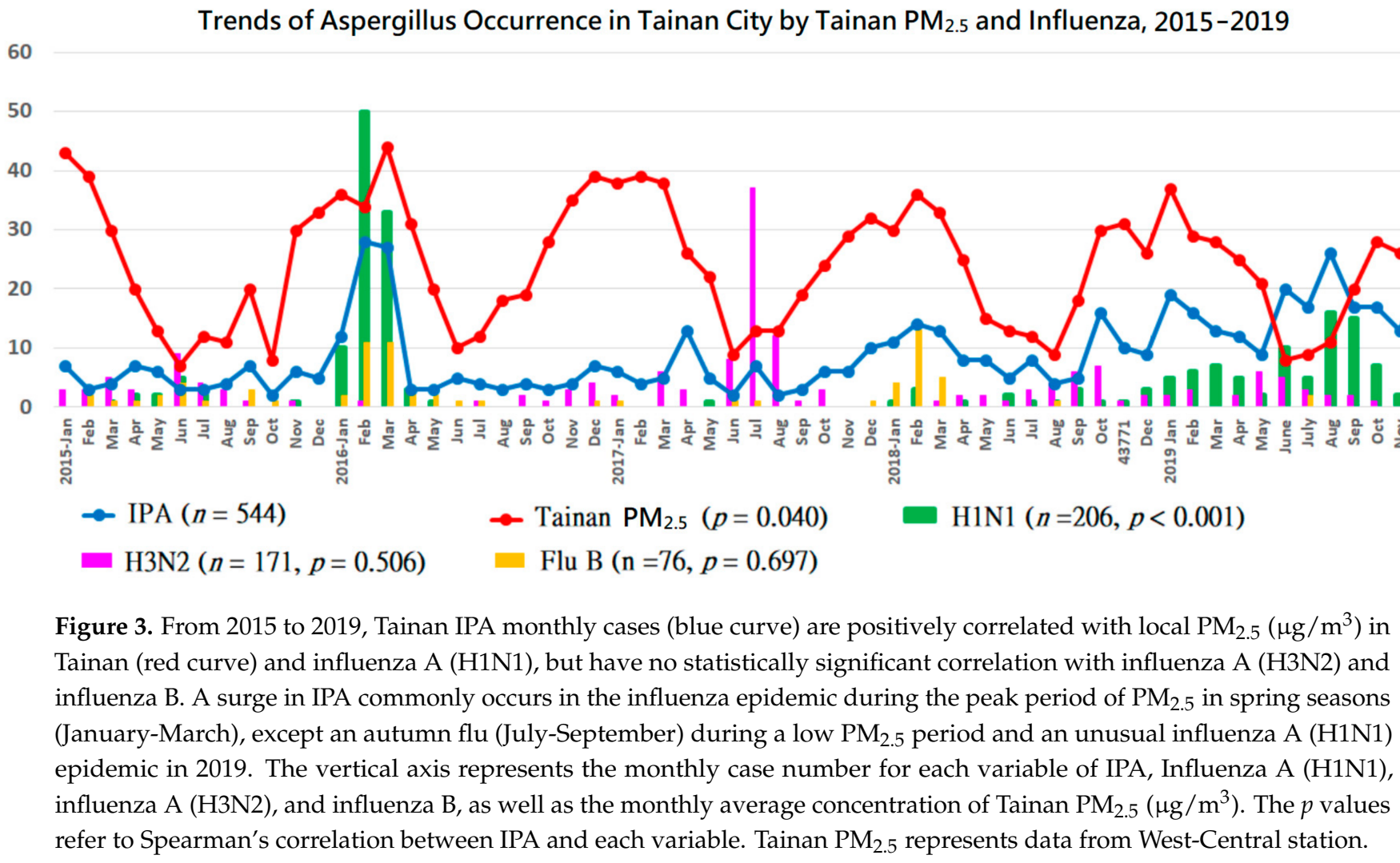

The effects of influenza and its subtypes on the occurrence of all IPA cases showed dynamic variation each year (Table 2). IPA was not correlated with influenza (all types) and subtypes in 2015 and 2018, but was positively correlated with a large epidemic of influenza (all types) in $2016(p=0.039)$. The development of IPA was negatively correlated with non-typed influenza A in 2017, with a correlation coefficient $\left(r_{s}\right)$ of $-0.596(p=0.041)$. Influenza A (H1N1) was positively correlated with IPA in the years 2015-2018 $(p=0.042)$, $2019(p=0.015)$, and 2015-2019 $(p<0.001)$. For influenza-associated IPA, $\%$ of IPA in severe influenza patients has a strong correlation with \% of IPA in each subtype of severe influenza during the retrospective stage and overall period in 2015-2019 (Table 3).

\subsection{Regression Analysis \\ Predictors for IPA (2015-2019)}

After exclusion of the less relevant observed factors by univariate analysis, three models were used to establish the predictive factors of IPA (Table 4). The best model is Model A, which adopts stepwise to choose the prediction model of the relevant factor, with $68.60 \%$ of the explanatory power. Influenza A (H1N1) significantly predicted IPA $(p<0.0001) . \mathrm{PM}_{10}$ in Tainan is also a significant predictor of IPA $(p=0.016)$, but $\mathrm{PM}_{2.5}$ only reached a trend $(p=0.085)$. However, non-typed influenza $\mathrm{A}$ is a negative predictor for IPA ( $\beta=-0.44, p=0.0302)$, which might be explained by the non-ICU influenza patients without further influenza subtyping in clinical practice. Non-severe influenza patients were less likely to develop IPA. 
Table 4. Predictors for IPA (2015-2019) by multiple linear regression.

\begin{tabular}{|c|c|c|c|c|c|c|c|c|}
\hline \multirow[b]{2}{*}{ Variables } & \multicolumn{2}{|c|}{ Univariate } & \multicolumn{2}{|c|}{$\begin{array}{c}\text { Model A } \\
\text { (Stepwise) }\end{array}$} & \multicolumn{2}{|c|}{$\begin{array}{c}\text { Model B } \\
(p<0.1)\end{array}$} & \multicolumn{2}{|c|}{ Model C $(p<0.05)$} \\
\hline & $\beta$ & $p$ & $\beta$ & $p$ & $\beta$ & $p$ & $\beta$ & $p$ \\
\hline Influenza (all) & 0.21 & $<0.0001$ & & & 0.34 & 0.0564 & 0.27 & 0.1158 \\
\hline $\mathrm{H} 1 \mathrm{~N} 1$ & 0.60 & $<0.0001$ & 0.90 & $<0.0001$ & 0.72 & $<0.0001$ & 0.76 & $<0.0001$ \\
\hline $\mathrm{H} 3 \mathrm{~N} 2$ & -0.15 & 0.3717 & 0.25 & 0.1258 & & & & \\
\hline Non-typed FluA & 0.46 & $<0.0001$ & -0.44 & 0.0302 & -0.92 & 0.0136 & -0.82 & 0.0267 \\
\hline FluB & 0.93 & 0.0034 & & & -0.46 & 0.1302 & -0.32 & 0.2761 \\
\hline Tainan $\mathrm{PM}_{2.5}$ & 0.14 & 0.0932 & 0.27 & 0.0845 & 0.09 & 0.1194 & & \\
\hline Tainan $\mathrm{PM}_{10}$ & 0.06 & 0.2142 & 0.27 & 0.0161 & & & & \\
\hline Zuoying $\mathrm{PM}_{2.5}$ & 0.06 & 0.4098 & -0.28 & 0.1151 & & & & \\
\hline Zuoying $\mathrm{PM}_{10}$ & 0.00 & 0.9259 & -0.16 & 0.1397 & & & & \\
\hline R square & & & & 0.6860 & & 0.6072 & & 0.5890 \\
\hline
\end{tabular}

$\beta$, beta coefficients.

\section{Discussion}

Influenza-associated IPA has emerged as a major healthcare challenge globally [13]. IPA might occur in up to $16-23 \%$ of severe influenza patients [5-8], similar to our current study of $13.0 \%$ during the retrospective stage and $21.7 \%$ in the prospective stage. Epidemiological association of IPA with $\mathrm{PM}_{2.5}$ and severe influenza (2015-2016) has been postulated in southern Taiwan, according to prior high-level $\mathrm{PM}_{2.5}$ exposure before a large influenza epidemic in Tainan City [9]. Higher levels of $\mathrm{PM}_{10}$ in ambient air during sandstorms were accompanied by higher concentrations of Aspergillus spores, as reported in Tainan City [1].

Sandstorm events often occur during the northeast monsoon season in Taiwan. By long-distance transport, the northeast monsoon originating from the Asian continent could transport $\mathrm{PM}_{10}$ and $\mathrm{PM}_{2.5}$, passing through Taiwan (from north to south) to downstream southern areas from autumn to the following spring annually $[14,15]$. Sandstorm dust is a prolific source of $\mathrm{PM}_{10}, \mathrm{PM}_{2.5}$, and bioaerosols including Aspergillus, other fungi, and bacterial isolates [14-16]. Therefore, urban air pollution depends greatly on seasonality and monsoons [17]. Concomitantly with the monsoon, the concentration of these potential health-risk bioaerosols has been higher in the receptor area (such as Tainan city in southern Taiwan) than in the imported area (such as Taipei City in northern Taiwan), due to the wakeflow effect with the slowdown of wind speed, resulting in high concentrations of $\mathrm{PM}_{2.5}$ in southern Taiwan, moderate concentrations in central Taiwan, and low concentrations in northern and eastern Taiwan (Taiwan Air Quality Monitoring Network, https: / airtw. epa.gov.tw/ENG/default.aspx accessed on 26 January 2021). However, the real impact of PM-associated bioaerosols on human fungal infections was not clearly delineated. A key aspect of limiting the fungus thread is first to ensure accurate correlation of fungal infection with PM pollution for those infected. Understanding the effects of ambient PM bioaerosols on IPA is essential for providing comprehensive medical care for these infected patients. In our current data, the IPA surge commonly occurred in spring during the northeast monsoon seasons with the highest levels of ambient $\mathrm{PM}_{2.5}$, implying that $\mathrm{PM}_{2.5}$ could be regarded as an indirect indicator of Aspergillus spore levels.

In this study, we first demonstrated that the trend of IPA has a statistically significant correlation with ambient $\mathrm{PM}_{2.5}$ and influenza (especially H1N1) in a secular 5-year data analysis. Because the incidence of IPA might be influenced by the motivation of physicians to initiate Aspergillus antigen testing, we conducted a prospective observational study to collect data in 2019 to compare with a retrospective study collecting data from 2015 to 2018. Overall, 544 IPA patients were identified, including 340 and 204 patients in the retrospective 4-year and prospective 1-year stages, respectively, suggesting a higher diagnostic motivation in 2019 (mean, 17 per month) than previously $(p<0.0001)$.

We used a cross-sectional sample of annual data and found a correlation in dynamic variance. In 2018, air pollution $\left(\mathrm{PM}_{2.5}\right.$ and $\left.\mathrm{PM}_{10}\right)$ rather than influenza primarily affected 
the IPA trend. The ambient $\mathrm{PM}_{2.5}$ levels from Zuoying in Kaohsiung City through Tainan City north to Xitun of Taichung were significantly correlated with IPA in Tainan. However, the $\mathrm{PM}_{10}$ levels from only the relatively restricted southern areas (Tainan City, Xinying District, and Zuoying District) were significantly correlated with IPA in Tainan. These data suggest that $\mathrm{PM}_{2.5}$ in the broadened area and $\mathrm{PM}_{10}$ in the restricted local area could affect IPA in Tainan City. Thus, we might construct a risk map indicating the vulnerability of different areas to Aspergillus infection in Taiwan.

In contrast, in 2019, the role of influenza A (H1N1) in Tainan City surpassed the roles of $\mathrm{PM}_{2.5}$ and $\mathrm{PM}_{10}$ in the correlation with Tainan IPA. The roles of PMs were probably confounded by autumn influenza A (H1N1) accompanied by an IPA surge during a lower PM season. The trends of IPA by influenza (all types), influenza A (H1N1), and $\mathrm{PM}_{2.5}$ were significant in the combined two stages of the study (2015-2019).

Our data supported the dynamic effects of influenza on the incidence of IPA [18]. Schwartz et al. reported that the effect of influenza on IPA might not be universal as the incidence of influenza-associated IPA varied (0-23.1\%) in different influenza seasons [18]. We expanded the dynamic effects to bioaerosols $\left(\mathrm{PM}_{2.5}\right.$ and $\left.\mathrm{PM}_{10}\right)$, which might alternatively replace the role of influenza in the IPA incidence in some seasons or years, and vice versa. This phenomenon could be best presented by the different effects in 2018 and 2019. Air bioaerosols $\left(\mathrm{PM}_{2.5}\right.$ and $\left.\mathrm{PM}_{10}\right)$ in Tainan City were significantly correlated with IPA in 2018, whereas influenza A (H1N1) in Tainan City reached a statistically significant correlation with Tainan IPA in 2019.

Throughout the two stages (2015-2019), IPA in Tainan was significantly linked to influenza (all types), influenza A (H1N1), and $\mathrm{PM}_{2.5}$ in Tainan City. Furthermore, using a stepwise regression model, influenza A (H1N1) and $\mathrm{PM}_{10}$ in Tainan City could significantly predict the occurrence of Tainan IPA. The results were consistent with a previous study in Tainan, which demonstrated a higher number of Aspergillus fungal spores in Tainan ambient air when coming across a season with a higher level of $\mathrm{PM}_{10}$ [1], and we further linked the $\mathrm{PM}_{10}$ to predict the development of IPA diseases. Furthermore, our data support a hypothesis that all the subtypes of severe influenza play a risk role for influenza-associated aspergillosis, as a strong correlation between them. However, the \% of influenza-associated aspergillosis did not reach the statistical significance of its correlation with $\mathrm{PM}_{2.5}$ and $\mathrm{PM}_{10}$. Therefore, IPA of all hosts, not limited to influenza patients, increased in a season of a large influenza epidemic or influenza A (H1N1) predominance, indicating other environmental variables in the influenza seasons that may affect the incidence of IPA, such as co-circulation of other respiratory viruses or respiratory pathogens, concurrent air pollution, or increasing search for IPA by physicians. These secular data suggest that ambient air pollution $\left(\mathrm{PM}_{2.5}\right.$ or $\mathrm{PM}_{10}$ ), as well as influenza factors (particularly H1N1 predominant seasons) can contribute alternatively or synergistically to the disease development of IPA. Research analyzing the risk hosts vulnerable to IPA in the pollution or influenza seasons is ongoing.

Our study shows its ability to detect risk factors for Aspergillus infections effectively, a much-needed tool for early screening of this fungus, particularly in high-risk seasons. Low motivation for testing GM for fungal infection in patients after severe influenza has been noticed outside Europe $[19,20]$. On the contrary, high vigilance of physicians to test the GM assay increased the detection of aspergillosis during the coronavirus disease 2019 epidemic in Taiwan [21]. In the current study, we identified the additional environmental risks of IPA. These critical events might afford aid for healthcare systems in starting up deployments (such as setting up an "IPA Watch" system and public education for medical mask wearing) to combat and prevent the fungal disease early on. Whether prevention measures are effective for fungal disease control also needs further investigation.

A limitation of this study might include the possibility of false-positive Aspergillus antigen testing and increasing the diagnostic motivation of physicians in the prospective observation study, and data retrieved from retrospective analysis in 2015-2018 that might underestimate the incidences of IPA. A positive GM index in serum $(>0.5)$ or in BAL $(\geq 1.0)$ has been proposed for influenza-associated pulmonary aspergillosis [22]. It might be more 
appropriate to use GM index $\geq 1.0$ in BAL for initiation of anti-fungal treatment based on the cost-effective evaluation [12]. Tests for GM in BAL and serum samples at a cutoff index $\geq 0.5$, aiming to increase test sensitivity for critically ill patients, were proposed by Schroeder et al. [10]. Besides, a higher GM index in lung excreta of $\geq 1.88$ might be a much better predictor of IPA compared to serum GM [23]. Our simplified GM cutoff index $\geq 0.5$ in serum, BAL, or endobronchial secretions could not support initiation of antifungal therapy, which might need an individualized or pragmatic approach. The main goal of the study was to assess the long-term trend of IPA influenced by the air pollution and influenza epidemic. The secular trend difference would not be influenced if a cut-off value has been constant. However, our data, including secular trends with different seasons, PM bioaerosols, and influenza factors, provide comprehensive epidemiology of risks for IPA to support early diagnosis of the fungus and continuous prospective monitoring of these environmental impacts on human health.

\section{Conclusions}

As far as we know, this is the first report to link air pollution and human aspergillosis. Air pollution and influenza seasons correlate with all IPA, but not necessarily with influenza-associated IPA. The latter correlates with all subtypes of severe influenza. The significant correlation of IPA with PM or influenza was not universal in each year, probably influenced by an epidemic scale in influenza season, influenza A (H1N1), $\mathrm{PM}_{2.5}$, and $\mathrm{PM}_{10}$, which might have predominantly circulated in some years. We demonstrated the dynamic variation of effects of the influenza epidemic, influenza A (H1N1), and local ambient PMs during the northeast monsoon seasons on IPA annually. We postulated that some ambient fungal spores could contribute to the development of IPA, especially in vulnerable hosts during an influenza A (H1N1) epidemic. These can potentially aid in increasing the motivation of physicians to initiate the diagnosis of IPA, particularly in early stages of pneumonia during appropriate seasons. Public health measures, such as observing $\mathrm{PM}_{2.5}$ and $\mathrm{PM}_{10}$ in northeast monsoon seasons and early diagnosis may be helpful for potentially affected patients and for containing the fungal epidemiology.

Supplementary Materials: The following are available online at https:/ / www.mdpi.com/2309-608 X/7/3/227/s1, Figure S1: The secular trend (2015-2019) of $\mathrm{PM}_{2.5}$ (monthly average) in Tainan City (left) decreased but was statistically insignificant $(p=0.3387)$. In contrast, the trend of monthly cases of influenza A (H1N1) in the Chi Mei medical systems (right) significantly increased (slope, 0.0357; $p=0.001$ ); Figure S2: A: Gradient of annually local ambient mean $\mathrm{PM}_{2.5}$ levels in 2018 , increasing from northern to southern Taiwan. Epidemiology of aspergillosis in Tainan City was correlated with local ambient mean $\mathrm{PM}_{2.5}$ levels higher than $20 \mu \mathrm{g} / \mathrm{m} 3$ in areas south to central Taiwan. B: Tainan IPA in 2018 is significantly correlated with the local $\mathrm{PM}_{2.5}$ pollution (Tainan and Zuoying) in southern Taiwan, but not correlated with $\mathrm{PM}_{2.5}$ pollution in distant areas, like northern and eastern Taiwan, with an interface at central Taiwan between Xitun and Fengyuan districts; Figure S3: In 2018, Tainan IPA (cases/month) in Tainan City is significantly correlated with $\mathrm{PM}_{10}(\mu \mathrm{g} / \mathrm{m} 3)$ at cities in southern Taiwan using Spearman's correlation calculation, including Tainan west-central area $(p=0.005)$, Xinying $(p=0.0008)$, and Zuoying $(p<0.0001)$, but not related to distant areas in central Taiwan, such as Xituin $(p=0.064)$ and Fenyuan $(p=0.102)$ and in northern Taiwan, such as Taipei Chongshan district $(p=0.190)$. The vertical axis represents monthly case number for Tainan IPA and also for monthly average concentrations of $\mathrm{PM}_{10}$ of various areas; Figure S4: From 2015 to 2019, Tainan IPA monthly cases (blue bar) are positive correlated to local $\mathrm{PM}_{2.5}(\mu \mathrm{g} / \mathrm{m} 3)$ curve in Tainan (red), but there is no statistically significant correlation of Tainan IPA with $\mathrm{PM}_{2.5}$ in distant areas, including Zuoying district of Kaohsiung City (black), Xitun district of Taichung City (yellow) and Chungshan District of Taipei City (green). The $p$ values represent Spearman's correlation calculation between Tainan IPA and $\mathrm{PM}_{2.5}$ of each area in various city. 
Author Contributions: W.-L.Y. was responsible for the integrity of the data and the accuracy of the data analysis. Concept and design: W.-L.Y. Acquisition, analysis, or interpretation of data: C.-M.C., H.-F.O., C.-H.H., and K.-S.C. Drafting of the manuscript: J.-W.L. and Y.-H.K. shared the same contribution. Critical revision of the manuscript: J.-W.L. and W.-L.Y. All authors have read and agreed to the published version of the manuscript.

Funding: This work was supported in part by a research grant from the Investigator-Initiated Studies Program (Project no. MISP \#57760 and no. MISP \#57761) from Merck Sharp \& Dohme Corp., Inc. USA. The opinions expressed in this paper are those of the authors and do not necessarily represent those of Merck Sharp \& Dohme Corp.

Acknowledgments: We thank Mei-Yu Su at the Department of Intensive Care Medicine, Chi Mei Medical Center, for data collection.

Ethical: We declare compliance with ethical standards approved by the Institutional Review Board of Chi Mei Medical Center (IRB no. 10801-002 and IRB no. 10711-008). We declare that the planning conduct and reporting of studies was in line with the Declaration of Helsinki, as revised in 2013.

Conflicts of Interest: All authors have no potential conflicts.

\section{References}

1. Wu, P.C.; Tsai, J.C.; Li, F.C.; Lung, S.C.; Su, H.J. Increased levels of ambient fungal spores in Taiwan are associated with dust events from China. Atmos. Environ. 2004, 38, 4879-4886. [CrossRef]

2. Cao, C.; Jiang, W.; Wang, B.; Fang, J.; Lang, J.; Tian, G.; Jiang, J.; Zhu, T.F. Inhalable microorganisms in Beijing's PM2.5 and PM10 pollutants during a severe smog event. Environ. Sci. Technol. 2014, 48, 1499-1507. [CrossRef]

3. Chao, H.J.; Chan, C.-C.; Rao, C.Y.; Lee, C.-T.; Chuang, Y.-C.; Chiu, Y.-H.; Hsu, H.-H.; Wu, Y.-H. The effects of transported Asian dust on the composition and concentration of ambient fungi in Taiwan. Int. J. Biometeorol. 2012, 56, 211-219. [CrossRef]

4. Kallawicha, K.; Tsai, Y.J.; Chuang, Y.C.; Lung, S.C.C.; Wu, C.D.; Chen, T.H.; Chen, P.C.; Chompuchan, C.; Chao, H.J. The spatiotemporal distributions and determinants of ambient fungal spores in the Greater Taipei area. Environ. Pollut. 2015, 204, 173-180. [CrossRef] [PubMed]

5. Guervilly, C.; Roch, A.; Ranque, S.; Forel, J.-M.; Hraiech, S.; Xeridat, F.; Adda, M.; Papazian, L. A strategy based on galactomannan antigen detection and PCR for invasive pulmonary aspergillosis following influenza A (H1N1) pneumonia. J. Infect 2012, 65, 470-473. [CrossRef] [PubMed]

6. Wauters, J.; Baar, I.; Meersseman, P.; Meersseman, W.; Dams, K.; De Paep, R.; Lagrou, K.; Wilmer, A.; Jorens, P.; Hermans, G. Invasive pulmonary aspergillosis is a frequent complication of critically ill $\mathrm{H} 1 \mathrm{~N} 1$ patients: A retrospective study. Intensive Care Med. 2012, 38, 1761-1768. [CrossRef] [PubMed]

7. Schauwvlieghe, A.F.A.D.; Rijnders, B.J.A.; Philips, N.; Verwijs, R.; Vanderbeke, L.; Van Tienen, C.; Lagrou, K.; Verweij, P.E.; Van De Veerdonk, F.L.; Gommers, D.; et al. Invasive aspergillosis in patients admitted to the intensive care unit with severe influenza: A retrospective cohort study. Lancet Respir. Med. 2018, 6, 782-792. [CrossRef]

8. Ku, Y.H.; Chan, K.S.; Yang, C.C.; Tan, C.K.; Chuang, Y.C.; Yu, W.L. Higher mortality of severe influenza patients with probable aspergillosis than those with and without other coinfections. J. Formos. Med. Assoc. 2017, 116, 660-670. [CrossRef]

9. Yu, W.-L.; Liu, W.-L.; Chan, K.-S.; Yang, C.-C.; Tan, C.-K.; Tsai, C.-L.; Chen, C.-M.; Chuang, Y.-C. High-level ambient particulate matter before influenza attack with increased incidence of Aspergillus antigenemia in southern Taiwan, 2016. J. Microbiol. Immunol. Infect. 2018, 51, 141-147. [CrossRef]

10. Schroeder, M.; Simon, M.; Katchanov, J.; Wijaya, C.; Rohde, H.; Christner, M.; Laqmani, A.; Wichmann, D.; Fuhrmann, V.; Kluge, S. Does galactomannan testing increase diagnostic accuracy for IPA in the ICU? A prospective observational study. Crit. Care 2016, 20, 139. [CrossRef]

11. Liu, J.-W.; Chen, Y.-H.; Lee, W.-S.; Lin, J.-C.; Chuang, Y.-C.; Lin, H.-H.; Liu, Y.-C.; Tang, H.-J.; Chen, Y.-S.; Ko, W.-C.; et al. Randomized noninferiority trial of cefoperazone-sulbactam versus cefepime in the treatment of hospital-acquired and healthcareassociated pneumonia. Antimicrob. Agents Chemother. 2019, 63, e00023-19. [CrossRef] [PubMed]

12. Donnelly, J.P.; Chen, S.C.; Kauffman, C.A.; Steinbach, W.J.; Baddley, J.W.; E Verweij, P.E.; Clancy, C.J.; Wingard, J.R.; Lockhart, S.R.; Groll, A.H.; et al. Revision and update of the consensus definitions of invasive fungal disease from the European Organization for Research and Treatment of Cancer and the Mycoses Study Group Education and Research Consortium. Clin. Infect. Dis. 2020, 71, 1367-1376. [CrossRef] [PubMed]

13. Liu, W.L.; Yu, W.L.; Chan, K.S.; Yang, C.C.; Wauters, J.; Verweij, P.E. Aspergillosis related to severe influenza: A worldwide phenomenon? Clin. Respir. J. 2019, 13, 540-542. [CrossRef]

14. Chang, S.Y.; Fang, G.C.; Chou, C.C.; Chen, W.N. Source identifications of $\mathrm{PM}_{10}$ aerosols depending on hourly measurements of soluble components characterization among different events in Taipei Basin during spring season of 2004. Chemosphere 2006, 65, 792-801. [CrossRef] [PubMed]

15. Chuang, M.T.; Lee, C.T.; Hsu, H.C. Quantifying PM $_{2.5}$ from long-range transport and local pollution in Taiwan during winter monsoon: An efficient estimation method. J. Environ. Manag. 2018, 227, 10-22. [CrossRef] 
16. Madhwal, S.; Prabhu, V.; Sundriyal, S.; Shridhar, V. Ambient bioaerosol distribution and associated health risks at a high traffic density junction at Dehradun city, India. Environ. Monit. Assess. 2020, 192, 196. [CrossRef] [PubMed]

17. Liu, Y.; Wu, J.; Yu, D.; Ma, Q. The relationship between urban form and air pollution depends on seasonality and city size. Environ. Sci. Pollut. Res. Int. 2018, 25, 15554-15567. [CrossRef]

18. Schwartz, I.S.; Friedman, D.Z.P.; Zapernick, L.; Dingle, T.C.; Lee, N.; Sligl, W.; Zelyas, N.; Smith, S.W. High rates of influenzaassociated invasive pulmonary aspergillosis may not be universal: A retrospective cohort study from Alberta, Canada. Clin. Infect. Dis. 2020, 71, 1760-1763. [CrossRef]

19. Thevissen, K.; Jacobs, C.; Holtappels, M.; Toda, M.; Verweij, P.; Wauters, J. International survey on influenza-associated pulmonary aspergillosis (IAPA) in intensive care units: Responses suggest low awareness and potential underdiagnosis outside Europe. Crit. Care 2020, 24, 84. [CrossRef]

20. Toda, M.; Beekmann, S.E.; Polgreen, P.M.; Chiller, T.M.; Jackson, B.R.; Beer, K.D. Knowledge of infectious disease specialists regarding aspergillosis complicating influenza, United States. Emerg. Infect. Dis. 2020, 26, 809-811. [CrossRef]

21. Lai, C.C.; Chen, C.M.; Liao, K.M.; Chao, C.M.; Chan, K.S.; Yu, W.L. A mysterious surge of aspergillosis among non-SARS-CoV-2 patients during COVID-19 pandemic. J. Microbiol. Immunol. Infect. 2021, 54, 156-158. [CrossRef] [PubMed]

22. Verweij, P.E.; Rijnders, B.J.A.; Brüggemann, R.J.M.; Azoulay, E.; Bassetti, M.; Blot, S.; Calandra, T.; Clancy, C.J.; Cornely, O.A.; Chiller, T.; et al. Review of influenza-associated pulmonary aspergillosis in ICU patients and proposal for a case definition: An expert opinion. Intensive Care Med. 2020, 46, 1524-1535. [CrossRef] [PubMed]

23. Rozaliyani, A.; Sedono, R.; Jusuf, A.; Rumende, C.M.; Aniwidyaningsih, W.; Burhan, E.; Prasenohadi, P.; Handayani, D.; Yunihastuti, E.; Siagian, F.E.; et al. A novel diagnosis scoring model to predict invasive pulmonary aspergillosis in the intensive care unit. Saudi Med. J. 2019, 40, 140-146. [CrossRef] [PubMed] 